\title{
The Effect of Freight Transport Time Changes on The Performance of Manufacturing Companies
}

\author{
Evangelos Sambracos ${ }^{1}$, Irene Ramfu ${ }^{2}$,
}

\begin{abstract}
:
Freight Transport Time (FTT) is an important resource for manufacturing companies, firstly as a cost driver of logistics processes and secondly as a key factor of customer satisfaction. Yet, there is a lot of controversy between researchers regarding the strength of the link between changes in transport time and business performance and the methods used to measure this effect. In this context, the aim of this paper is to estimate the effect that changes in freight transport time have on the economic performance of transport consuming manufacturing companies. With the use of System Dynamics Modelling a simulation model is built identifying the role of FTT in the internal supply chain of a Make to Stock manufacturer. Changes in FTT are introduced in the system affecting the production materials inventory replenishment time and the delivery to consumer time. Simulation results suggest that the effect of FTT changes depend highly on the structure of the company's decision making process. Through the development and simulation of several scenarios it is evident that information feedback about changes in FTT if interpreted and processed by different decision rules and strategies can lead to different results allowing companies to fruitfully - or not - reap the benefits of improved FTT.
\end{abstract}

Key Words: Freight Transport Time, Manufacturers, Performance, Systems Dynamics

\section{JEL Classification :}

\footnotetext{
${ }^{1}$ University of Piraeus, Dept. of Economics, 80, Karaoli and Dimitriou Str. Piraeus, 18534, Greece, email: sambra@ unipi.gr

${ }^{2}$ University of Piraeus, Dept. of Economics, 80, Karaoli and Dimitriou Str. Piraeus, 18534, Greece, email: teru@unipi.gr
} 


\section{Introduction}

While the discussion of competitiveness and economic development usually focuses on the macroeconomic, political, legal, and social circumstances that underpin an economy, progress in these areas is indeed necessary but is not always considered to be a sufficient prerequisite for the creation of wealth. According to the World Economic Forum, wealth is actually created by the productivity with which a country can utilize its human, capital, and natural resources in order to produce goods and services and therefore it ultimately depends on the microeconomic capability of the economy (Porter et al. 2007).

Numerous microeconomic factors have been identified that operate directly on firms in affecting productivity. Porter et al., $(2007,2008)$ group these factors into three interrelated areas: the sophistication of companies' operations and strategies, the quality of the national business environment, and the externalities arising from the presence of clusters of related and supporting industries. Within this framework, productivity rises when companies improve the operational effectiveness of their activities, get closer to global best practices; pursue distinctive strategies in marketing, production, logistics, service delivery (Havlicek et al. 2013); introduce corporate governance where is possible (Thalassinos and Zampeta, 2012). The quality of the business environment can be understood in terms of four interrelated dimensions: The efficiency, quality, and specialization of the inputs available to firms (resources and infrastructures), the context of rules in which for firm strategy and rivalry take place, the quality of local demand conditions, and the presence of the related and supporting industries (Porter, 1990). Finally, the location of companies into clusters allow them to exploit externalities and complementarities of various types (agglomeration economies).

In the Global Competitive Report (2012) infrastructure is identified as one of the 12 pillars of productivity, on the ground that it determines the location of economic activity and reduces the effect of distance between regions, integrating the national market and connecting it at low cost to markets in other countries and regions. Effective modes of transport-including quality roads, railroads, ports, and air transport - enable entrepreneurs to get their goods and services to market in a secure and timely manner (World Economic Forum, 2012:5). Yet, despite the wealth of information regarding the contribution of freight transportation to the economy, there is a lot of debate on the linkage between these two phenomena (US DOT FHWA, 2004).

While in theory, transportation projects and policies leading to savings in freight transport time (FTTS) are expected to have a positive effect on carriers' performance reducing time related transport costs and improving service, this is not always the case for their customers: shippers and consignees. Microeconomic 
research, particularly cost-benefit analysis (CBA) does not fully account for the benefits of transport improvements that accrue to shippers from cost savings and service improvements (US DOT FHWA, 2004). Despite efforts to expand CBA in order to capture the full effect of FTTS, serious consideration has been raised regarding the ability of existing data collection methods to safely elicit the value of FTTS for shippers (De Jones, 2000; Massiani, 2003; Zambarini and Reggiani 2007, Ramfou, 2012, Sambracos and Ramfou, 2013). Most methods assume that best practices as a result of FTT changes will be quickly identified and implemented by companies, therefore increasing their performance. However, Sterman (2000) argued that the same information if interpreted and processed by a different decision rule will yield different decisions and therefore results. Sambracos and Ramfou (2013) illustrated that indeed different decisions and strategies stemming from changes in FTT (FTTC) may lead to different performance results.

This paper focuses of the demand side of the transport market and aims at investigating the ways in which FTTC can affect business performance of transport consuming companies. In the next section relative literature on the microeconomics effects of FTTC on shippers is discussed along with the methods used to quantify these effects. In the third section, with the use of System Dynamics modeling, the paper considers the effect of freight transport time changes (FTTC) on manufacturers applying a Make to Stock strategy. The paper ends with a discussion of the simulation results and addresses issues to be discussed in future research.

\section{Literature Review}

\subsection{Microeconomic Effects of FTTC}

Freight transportation performs an intermediary role in the supply chain providing the bridging function between supply and demand for goods and acting as glue that holds the supply chain together (Coyle et. al. 2010). Consequently, freight transport demand is a derived one, resulting from the spatial interaction between complex business processes. It is evident that in order to understand the value of transport time for companies it is necessary to consider the wider context of logistics, production and trade activities, through which time acts as a resource (Tavasszy and Bruzelius, 2005).

Based on the microeconomic theory, the value of freight transport time savings (VFTTS) is defined as the benefit that derives from a unit reduction in the amount of time necessary for the door to door transporting of goods. According to this definition, FTT includes travelling and non-travelling times i.e. for operations performed between the origin and the final destination of the shipment such as cross-docking, intermediate warehousing, grouping - degrouping, border-crossing etc (Massiani, 2003). 
The US Federal Highway Administration (US DOT FHWA, 2001) classified benefits from FTTS as first, second and third order ones. First order benefits include immediate time related transport cost reductions to carriers and shippers. Carrier effects include reduced vehicle operating times and costs through optimal routing and fleet configuration. Transit times may affect shipper in-transit costs such as for spoilage, and scheduling costs for inter-modal transfer delays and port clearance. In the short run nothing changes for shippers except for the cost of freight movement, since they continue to ship the same volume of goods between the same points.

Second order benefits include long term reorganization gains that refer to adjustments that transport consumers (shippers and consignees) make in their logistical arrangements in response to lower costs of freight movement resulting from FTTS (Mohring and Williamson, 1969). Tavasszy (2008) classified firm's responses to FTTS into three categories. The first, transport reorganization involves changes in routes, type of vehicle, modes of transport with time influencing the amount of inventory in transit and the value of the product. The second, inventory reorganization involves the number, location and volume of inventories with time determining which clients can be served by which warehouse within service level targets. Finally, production reorganization involves a shift between materials used, changes in production location or basic production technology changes.

Boston Logistics Group (US DOT, 2006) identified several mechanisms that link FTTS and lower transportation costs to supply chain benefits that include:

- sourcing from less expensive but more distant suppliers and reducing shipment size and inventory, thereby creating lean benefits;

- operating fewer, larger plants at the same delivered price and relocating existing plants to lower-cost areas;

- reducing average shipment size, adding to manufacturing flexibility;

- shifting warehouse stock to in-transit inventory, which further reduces warehouse operating cost, reducing the need for logistics overhead;

- rationalizing the vehicle fleet and the warehouse labour needed to serve the same customer demand (fewer vehicles, drivers, warehousing and receiving staff).

Further, they identified several "shadow" benefits that are expected to result from firms' ability to convert cost savings into price reductions, stimulating demand and revenue growth, to leverage lower transportation costs and offer better service levels for the same price, or same service level for lower price, or higher service levels for higher price and shorter order-to-delivery lead times and to create "on-demand" supply chains where flexible manufacturing and distribution results in less waste and more sales at higher margins (US DOT, 2006). Third order benefits are longer term benefits that derive from additional reorganization effects that include among other 
the design and production of improved products and/or new products (US DOT FHWA, 2001). FTTC benefits have a dynamic character since they evolve over time and do not strictly coincide with the time of the improvement. Boston Logistics Group for example proposed a 24 month timetable of benefits realization (US DOT, 2006). Of course such a timetable is only indicative since in reality it is difficult to identify a generic timetable because the time lag between the FTTS, the reaction of the firms to it and the materialization of the benefit (or loss) varies. Current analysis indicates that in theory FTTC can affect the performance of shippers, however there is no consensus with regard to the magnitude of this effect. Several methods have been proposed in an effort to elicit the value of FTTC.

\subsection{Measuring the Value of FTTC}

Under the capital value or factor cost approach, the value of FTTC is estimated on the thinking that FTTC translate to decreases (or increases) in transport and freight cost for the transport consuming company (Tavasszy and Bruzelius, 2005). Transport costs include vehicle costs dependent on time (fuel, maintenance, tires, vehicle taxes and insurance, depreciation), drivers and maintenance workers' wages, necessary overheads (such as training and social security payments) (Odgaard et al. 2005).

In transport demand modelling, willingness to pay for FTTS can be obtained using disaggregate behavioral and inventory models with both types gathering information regarding the behavior of stakeholders (Winston, 1983). In the first case, the decision maker in charge of the shipment is considered as a consumer of transport services that faces a utility maximization problem, taking into consideration parameters such as the cost and quality of the service for each mode and the uncertainty associated to choosing that mode. The value of FTTS constitutes the marginal rate of substitution between transport time and transport cost and is given by the estimated coefficient for time divided by the cost coefficient (Feo-Valero et al. 2011).

Inventory models share another view and incorporate variables related to production, such as shipment size and frequency of shipment, aiming at maximizing a profit function. They consider the trade-off between inventory and transportation in an effort to minimize total logistics cost, while maintaining the necessary level of customer service bearing in mind demand and lead time uncertainty. According to Baumol and Vinod (1970) goods while being transported are "inventory on wheels" and the total transport cost function is the sum of four cost categories: direct shipping cost (freight rate, insurance etx.), carrying cost in transit (interest, deterioration, pilferage rate), cost of ordering and processing and inventory carrying costs. In this framework the value of time for the shippers has two components: the 
reduction of inventory costs occurring during transportation and the reduction of the costs of holding inventories to respond to unexpected change in the demand.

Data for disaggregated models can be obtained by means of revealed preference (RP) or stated preference (SP) experiments. Several authors have provided a review of studies on the valuation of freight transport time. De Jong (2000) concluded that mostly data come from contextual, highly customized SP computer interviews with carriers and shippers who are asked to compare pairs of alternatives, using logit models with linear utility functions. Zambarini and Regiani (2007) and Feo-Valero et al. (2011) confirmed the dominance of SP surveys and behavioral models and also showed a remarkable variation in the values that users put on FTTS. Such differences were explained partly by the different methods adopted to collect observations and partly by the influence exerted by contextual factors such as the trip distance, the country where the study is developed, the per-capita GDP, the category of transported goods, the transport unit used.

All methods share serious limitations. The factor cost method carries the risk of underestimating the value of FTTS because while there appears to be agreement regarding the type of variable costs that should be taken into account, no uniform criteria exists when deciding whether or not to consider fixed costs and costs that are not directly related to the transport activity, such as inventory costs (De Jong, 2000). Additionally, it does not account for potential changes in revenues associated with time changes or for benefits not captured through the market price and finally it focuses only on first order, short-term effects of FTTC on transport operators and shippers (Zamparini and Reggiani (2007).

Revealed Preference (RP) surveys face practical limitations basically associated with the high survey costs, the inability to distinguish the trade-offs between alternatives, the difficulty to detect the relative importance of variables that do not dominate the observed behavior, the difficulties in collecting responses for new services, alternatives and policies, the ambiguity of the choice set (Morikawa, 1994, Ortúzar and Willumsen, 2011).

Stated Preference data share the problem of 'hypothetical bias' a term used to denote the deviation from real market evidence (Hensher, 2010). Zambarini and Regiani (2007) identified many reasons why that happens that include the dependence of the results on the capability of the researcher to choose and describe the alternatives amongst which the firm's representatives have to choose, the possibility that the answer does not reflect the behavior that the respondent would adopt in a real situation, the fact that the respondent may not be aware of all the gains and losses that a FTTC might generate for the firm. Hensher et al., (2005) raised questions about the influence that the design of the experiments has on the behavioral outputs 
of such models and identified a variety of information processing strategies that managers may adopt.

Another issue is the difficulty to identity the decision-maker or makers in a firm. While existing approaches assume that there is a unitary decision-making process in reality there are diverse actors involved in the process coming from the procurement, production, inventory, marketing or distribution department of the firm. They may have no control or knowledge of all decisions made throughout the firm's supply chain plus their requirements may be conflicting (Danielis et al. 2005). Additionally, it is unrealistic to assume perfect knowledge on the part of the firm, especially when it comes to estimating long term, reorganization effects. The approach proposed by FHWA (2001) recommends the use of SP surveys in order to estimate logistics costs savings from FTTS assuming full information and certainty about future decisions. Certain impediments exist that make this assumption unrealistic and include the existence of dynamic complexity due to the time delays between taking a decision and its effects, dynamicity and nonlinearity of systems, limited information, poor scientific reasoning skills, private agendas leading to game playing and misperceptions of feedback hindering peoples' ability to understand the structure and dynamics of complex systems (Sterman, 2000).

Sambracos and Ramfou (2013) proposed a framework built on the thinking that the value of FTTC reflects the anticipation of freight consuming companies on the effect that these changes will have on their financial performance. Bearing in mind the existence of diverse actors all business processes affected by FTTS and tradeoffs are considered and a System Dynamics model was built and simulated for the case of a retailing company. In the remaining sector of the paper this framework is further extended and applied for the case of a manufacturer applying a make to stock production strategy.

\section{Estimating the Effect of FTTC on Manufacturers}

\subsection{The Structure of the Model}

The central core of many industrial companies is the process of production and distribution. Freight transportation facilitates both processes since it allows for the inbound transportation of production materials from the supplier and the outbound transportation of finished goods to the customer. In this analysis, we consider a manufacturer that applies a Make to Stock strategy for both product materials' and final goods' inventories. The company is part of a traditional supply chain meaning that inventories are set according to demand information flowing upstream from the next tier of the supply chain (e.g. wholesaler or retailer). 
Figure 1 illustrates the policy structure diagram as described by Sterman (2000) and Morecroft (2007) of a typical manufacturer depicting its internal supply chain. It consists of the stock (represented by rectangles and act as accumulations) and flow structure of the system (represented by pipes pointing into and out of the stock) for the ordering, acquisition, storage of materials, transformation into finished goods (production) and transportation to customers. Also, it includes the decision structure governing the flows that include policies for ordering production materials, scheduling production, fulfilling orders from production and customers (represented as rounded rectangles).

In brief, the manufacturer receives orders from customers and then adjusts production in order to meet demand. Procurement managers order materials from suppliers in order to maintain materials inventories sufficient for production to proceed at the desired date. They must adjust for variations in demand, delivery delays and possible restrictions in capacity and order quantity. The manufacturer maintains a stock of Materials Supply Line indicating materials that have been ordered but not yet received, Materials Inventory, from where materials are entering into the production process, Work in Process Inventory with materials being transformed into finished goods, Finished Goods Inventory from where customer orders are filled as they arrive and Goods in Transit indicating goods transported to the customer. Inflows to these stocks add to them while outflows subtract from them, while both are subject to several decision rules. Finally, in order to measure performance business costs and revenues are considered. 
Figure 1. The policy structure of a manufacturer

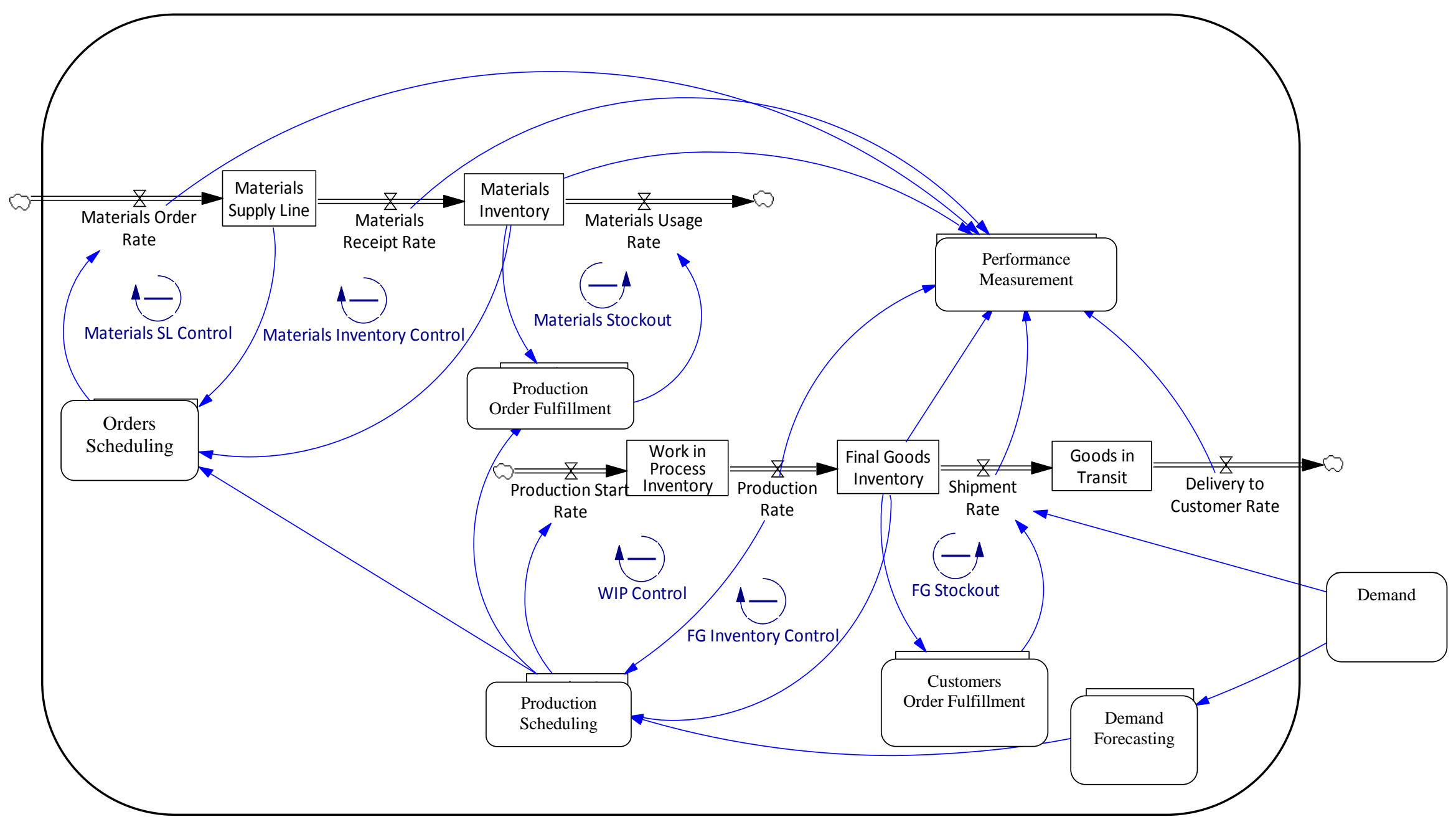


In the model there are six negative feedback loops that are the basis of the systems perspective where the typical thinking style is not linear but circular starting from a problem expressed as a discrepancy between a goal and the current situation, moving to a solution and then back to the problem. Problems do not just appear but rather spring from other decisions and actions that may have obvious or even hidden side effects (Morecroft, 2007). The Materials Supply Line (SL) Control and Materials Inventory Control loops adjust Materials Order Rate in order to move the levels of the materials supply line (SL) and inventory to their desired levels. The same applies for Work in Process (WIP) Control and Finished Goods (FG) Inventory Control loops whose aim is to adjust the WIP and FG Inventory to their desired levels. The Stockout loop of materials and finished goods regulates shipments to production and customers as inventories vary and the company may not be able to satisfy demand. Finally, Demand is exogenous (mapped outside the borders of the model). The analytical structure of the model is depicted in figure 2 and analyzed below.

\subsection{Model assumptions and parameters setting}

Several assumptions were made regarding customer demand, inventory policy, production scheduling, transportation and other operational details. Some of them are rather conservative but they apply in an effort to simplify the model and discuss the effects stemming mainly from FTTC.

Actual Customer Demand ( $A D)$ is considered to be exogenous and normally distributed with a mean of 20 units of finished products per day and a standard deviation of 5. Expected Demand (ED) is estimated at 20 units of finished products per day.

The model assumes a continuous review inventory system where the Desired Finished Goods Inventory (DFGI) and the Desired Materials Inventory (DMI) depend on the expected demand for finished goods from customers and materials from production and the days of coverage the company desires to have, according to the following formulas:

DFGI $=$ Expected Demand (ED) $x$ Inventory Days of Sales (IDS)

DMI $=$ Desired Materials Usage Rate $($ DMUR $)+$ Materials Inventory Coverage (MIC)

The order quantity (materials/day) placed with the upstream supplier is based on the Materials Supply Line Gap (MSLGAP) that is the difference between the Actual Materials Supply Line (MSL) and Desired Materials Supply Line (DMSL), the 
Materials Inventory Gap (MIGAP) denoting the gap between Actual Materials Inventory (MI) and Desired Materials Inventory (DMI), the Work in Process Gap (WIPGAP) that is the gap between Actual (WIP) and Desired WIP (DWIP), the Finished Goods Inventory Gap (FGIGAP) denoting the gap between Actual Finished Goods Inventory (FGI) and Desired Finished Goods Inventory (DFGI) as well as on any restrictions that exist in the materials order quantity. In the model it is assumed that due to negotiations with the supplier the company must place orders that satisfy the condition:

Materials Order Rate (MOR) $\geq$ Minimum Order Quantity (MOQ) 
European Research Studies, XVII (1), 2014 E. Sambracos, I. Ramfu

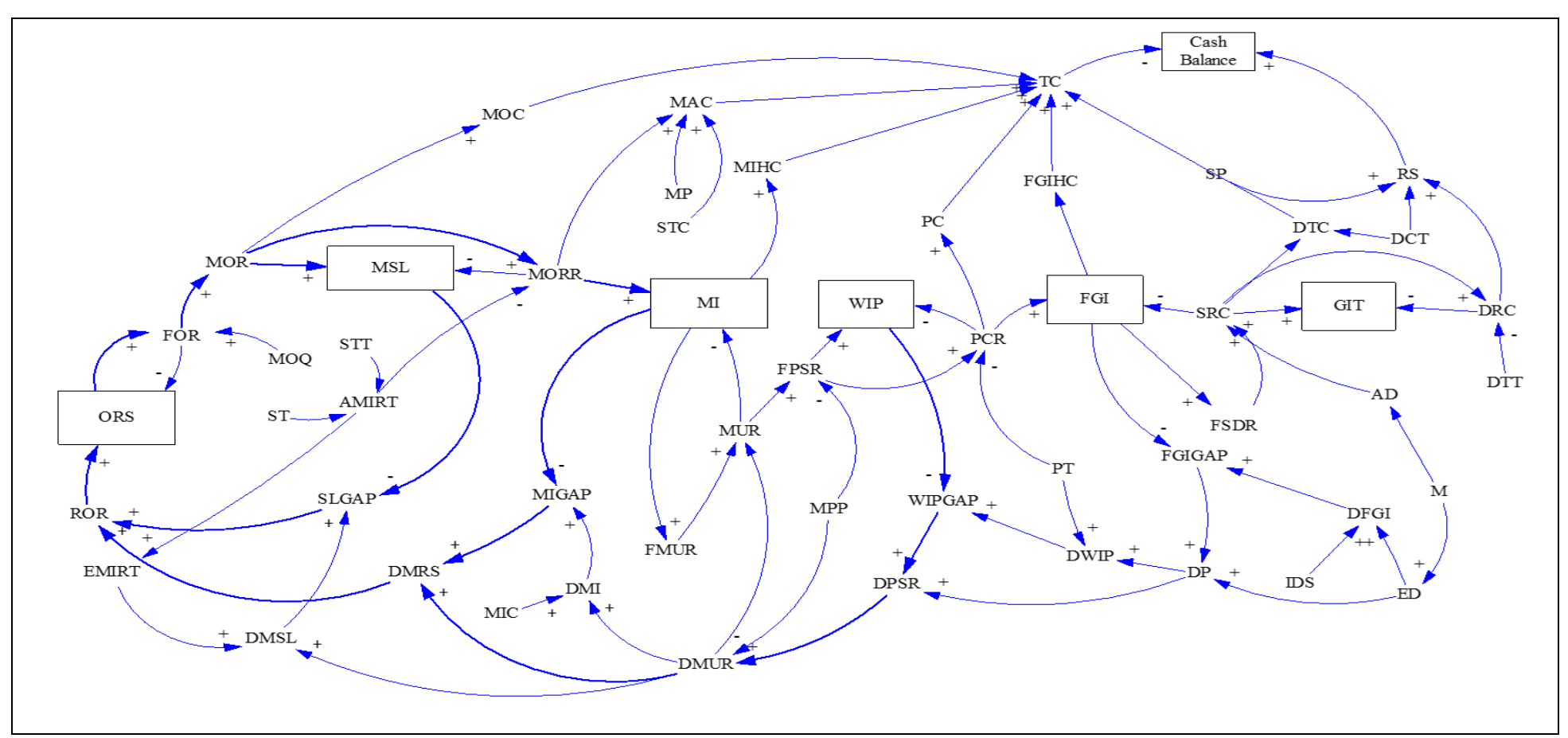

Figure 2. Analtical model structure 
Therefore,

Materials Order Rate $(\mathrm{MOR})=£($ MSLGAP, MIGAP, WIPGAP, FGIGAP, MOQ $)$

Required Materials Orders (ROR) are accumulated in the stock Orders to Supplier $(O R S)$ and are finally released to the supplier after the MOQ condition has been satisfied.

Freight transportation time affects the materials inventory replenishment time that is the total time that elapses between placing an order to the supplier and receiving it. This time typically consists of the time to transmit the order (in the model considered to be minimum due to modern information technology), the time for the supplier to process the order and have the ordered goods ready for dispatch (in the model considered as exogenous one since the manufacturer cannot affect it), the time to transport the ordered goods and the time required to unload and store goods in the company's warehouse (in the model considered to be minimum due to modern storage and information technology). For simplicity reasons it is assumed that:

Actual Materials Inventory Replenishment Time $($ AMIRT $)=$ Supplier Time (ST) + Sourcing Transportation Time (STT)

For the base case scenario it is assumed that the company is aware of AMIRT at all stages of simulation, and use it as an input in order to estimate the Desired Materials Supply Line (DMSL) based on the thinking that the company desires incoming orders and material inventory to cover the lead time between placing and receiving the order. Therefore:

AMIRT $=$ Expected Materials Inventory Replenishment Time $($ EMIRT $)$

DMSL $=$ Desired Materials Usage Rate (DMUR) $\mathrm{x}$ EMIRT

DMUR $=$ Desired Production Start Rate (DPR) $x$ Materials per Product (MPP)

Accordingly, transportation time affects the Delivery Time to customer (DTT) along with other order processing times that are considered to be minimum. It is assumed that goods are transported to the customer on demand without order batching so each time the company receives an order it is immediately served providing there is adequate inventory. Every time a shipment commences (Shipment Rate to Customer - SRC) the stock Goods in Transit (GIT) increases until goods are delivered to the customer (Delivery Rate to Customer - DRC). Therefore: 
$G I T t_{t}=\int_{t_{0}}^{t}(S R C-D R C) d s+G I T_{t_{0}}$

With regard to measuring performance, Kaplan and Norton's (1996) quotation that improvements in the planning and execution of internal processes will benefit a company only when they can be translated into financial performance in the form of revenue growth, cost reduction and better asset utilization is taken into consideration. In the model the metric Cash Balance (CB) is used in the form of stock that is increased by cash inflows stemming from Revenues from Sales (RS) and decrease by cash outflows stemming from Total Cost (TC) based on the following formulas:

$C_{t}=\int_{t_{0}}^{t}(R S-T C) d s+C B_{t_{0}}$

Revenue from Sales $(R S)=$ Delivery to Customer Rate $(D C R) \times$ Selling Price $(S P)$

Total Cost $(\mathrm{TC})=\mathrm{MOC}+\mathrm{MAC}+\mathrm{MIHC}+\mathrm{FGIHC}+\mathrm{PC}+\mathrm{DTC}$

Materials Ordering Cost (MOC) is the fixed cost per order irrespectively of the order quantity, Materials Acquisition Cost $(M A C)$ is the cost of the ordered materials plus the transportation cost, Materials Inventory Holding Cost (MIHC) and Finished Goods Inventory Holding Cost (FGIHC) is the cost for holding one item in stock, Production Cost (PC) is the cost of production and Delivery Transportation Cost $(D T C)$ is the cost for transporting goofs to the customer.

Table 1 shows the specific parameter settings used in this model, including the initial settings for all stock. Initial values were estimated so as to ensure that the model starts with zero gaps between the actual and the desired states of the system. No restrictions are assumed with regard to warehouse, production or transportation capacity. The reason for assuming unconstrained capacity is to simplify the model, making it easier to interpret the results that are the result of FFTC and not confounded by constrained production, transport or warehouse capacity. These assumptions could be relaxed and addressed in future research. 
Table 1. Parameter settings of the model (Base Case)

\begin{tabular}{|l|l|}
\hline Actual Demand (AD) & $\begin{array}{l}\text { Normally distributed, Mean = 20products/day, } \\
\text { SD }=5 \text { products /day, maximum number of } \\
\text { orders }=30 \text { products /day and minimum number } \\
\text { of orders }=0 \text { products } / \text { day. }\end{array}$ \\
\hline Expected Demand (ED) & 20 products/day \\
\hline Minimum Order Quantity (MOQ) & 1000 materials/order \\
\hline Supplier Time (ST) & 2 days \\
\hline $\begin{array}{l}\text { Sourcing Transportation Time } \\
\text { (STT) }\end{array}$ & 8 days \\
\hline $\begin{array}{l}\text { Delivery Transportation Time } \\
\text { (DTT) }\end{array}$ & 3 days \\
\hline Production Time (PT) & 2 days \\
\hline Materials Order Cost (MOC) & $3 € /$ order \\
\hline $\begin{array}{l}\text { Materials Purchase Price (MP) exl. } \\
\text { transportation cost }\end{array}$ & $8 € /$ material \\
\hline $\begin{array}{l}\text { Selling Price } \\
\text { transportation cost }\end{array}$ & $100 € /$ product \\
\hline Sourcing Transportation Cost (STC) & $2 € /$ material \\
\hline $\begin{array}{l}\text { Materials Inventory Holding Cost } \\
\text { (MIHC) }\end{array}$ & $10 € /$ material/year or \\
\hline $\begin{array}{l}\text { Finished Goods Inventory Holding } \\
\text { Cost (FGIGCC) }\end{array}$ & $\begin{array}{l}20 € / \text { product/year or } \\
20 / 365 \mathrm{x} \text { FGI } € / \text { day }\end{array}$ \\
\hline Production Cost (PC) & $10 € /$ product \\
\hline $\begin{array}{l}\text { Product Delivery Transportation } \\
\text { Cost (DCT) }\end{array}$ & $5 € /$ product \\
\hline $\begin{array}{l}\text { Materials Inventory } \\
\text { (MIC) }\end{array}$ & 5 days \\
\hline Inventory Days of Sales (IDS) & 3 days \\
\hline Materials Per Product (MPP) & 5 materials/product \\
\hline Materials Supply Line (MSL) & Initial Value $=1000$ \\
\hline Materials Inventory (MI) & Initial Value $=500$ \\
\hline Work in Process (WIP) & Initial Value $=40$ \\
\hline Finished Goods Inventory (FGI) & Initial Value $=60$ \\
\hline Goods in Transit & Initial Value $=20$ \\
\hline
\end{tabular}




\subsection{Scenario Building and Simulation Results}

The model was simulated for 1000 days and results were produced on a daily basis (time step $=1$ day) using Vensim Ple software. For the Base Case run, all parameters including transportation times are kept constant and Cash Balance is estimated. Changes in transportation time can occur at two points affecting the Sourcing Transportation Time (STT) or/and the Delivery Transport Time (DTT). Changes were introduced at day 200 and several scenarios were built based on different assumptions regarding the reaction of the firm to these changes that are presented in table 2.

Table 2. Scenarios of FTTC and Company Reaction

\begin{tabular}{|c|c|c|c|}
\hline Scenario & $\begin{array}{l}\text { Sourcing } \\
\text { Transportation } \\
\text { Time - STT (days) }\end{array}$ & $\begin{array}{l}\text { Delivery } \\
\text { Transportation } \\
\text { Time - DTT (days) }\end{array}$ & Company Reaction \\
\hline $\begin{array}{c}\text { Base } \\
\text { Case }\end{array}$ & 8 & 3 & No \\
\hline 1 & $6($ at $\mathrm{t}=200)$ & 3 & EMIRT=10days \\
\hline 2 & $6($ at $\mathrm{t}=200)$ & 3 & $\begin{array}{c}\text { EMIRT }=8 \text { days at } \\
\mathrm{t}=200)\end{array}$ \\
\hline 3 & $6($ at $\mathrm{t}=200)$ & 3 & $\begin{array}{c}\text { EMIRT }=8 \text { days at } \\
\mathrm{t}=230)\end{array}$ \\
\hline 4 & $10($ at $\mathrm{t}=200)$ & 3 & $\begin{array}{c}\text { EMIRT }=10 \text { days } \\
\mathrm{t}=200)\end{array}$ \\
\hline 5 & $10($ at $\mathrm{t}=200)$ & 3 & $\begin{array}{c}\text { EMIRT } \mathrm{n}=12 \text { days } \\
\mathrm{t}=230)\end{array}$ \\
\hline 6 & $10($ at $\mathrm{t}=200)$ & 3 & No \\
\hline 7 & 8 & $2(\mathrm{at} \mathrm{t}=200)$ & No \\
\hline 8 & 8 & $4($ at $\mathrm{t}=200)$ & \\
\hline & & & \\
\hline
\end{tabular}

Simulations of scenarios 1-6 highlight some very important conclusions. A change in Sourcing Transportation Time (STT) will result in a change in the Actual Materials Inventory Replenishment Time (AMIRT). Research usually implies that companies will immediately consider this change and adjust the Expected Materials Inventory Replenishment Time (EMIRT) that affects the Desired Materials Supply Line (DMSL) and ultimately the Materials Order Rate (MOR). Assuming a decrease in STT by 2 days at time 200 and comparing the Base Case with Scenarios 1-3 it is revealed that Cash Balance is improved if the company immediately adjust EMIRT to match AMIRT (Scenario 2, figure 3). The results for the case of an increase of STT are even more intriguing, since they show that an increase in transport time will have a positive effect on CB if the company does not adjust EMIRT and continues to apply a materials ordering policy based on a 10 days Materials Inventory Replenishment Time (Scenario 4). The model allows for the tracing of the reasons 
behind this behavior. As it can be observed from Table 3 the company in scenario 4 faces lower costs in comparison with the other alternatives since it places fewer orders, receives fewer materials from the supplier and also keeps smaller materials inventory.

Figure 3. Simulation Results for a Change in Souring Transportation Time (STT) and Delivery Transport Time (DTT)

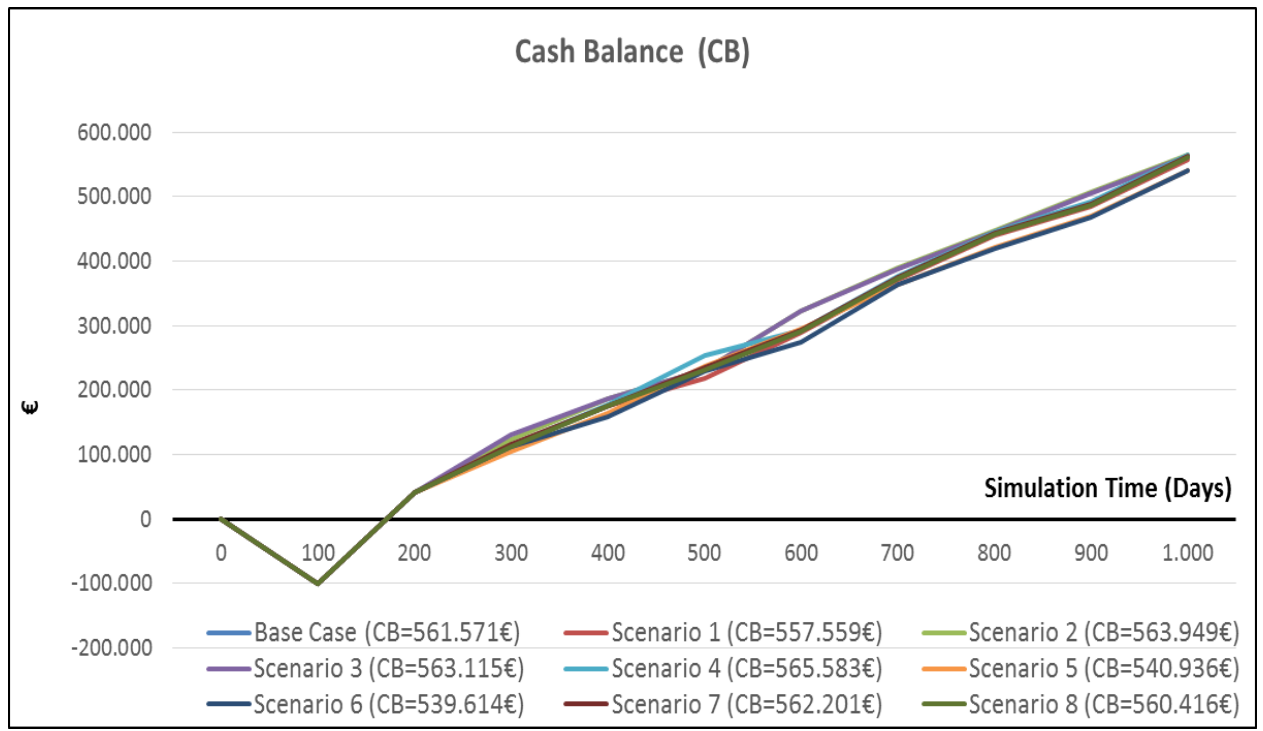

Table 3. Scenarios Result of FTTC and Company Reaction

\begin{tabular}{|l|l|l|l|l|l|l|l|}
\hline & Base Case & Scen. 1 & Scen.2 & Scen.3 & Scen.4 & Scen.5 & Scen.6 \\
\hline Total Materials Ordered & 96.160 & 96.160 & 95.355 & 95.355 & 96.160 & 96.500 & 96.500 \\
\hline Total Materials Received & 94.365 & 94.365 & 95.355 & 95.355 & 94.365 & 95.215 & 95.215 \\
\hline Average Materials Inventory & 4.954 & 5.100 & 4.507 & 4.537 & 4.808 & 5.397 & 5.445 \\
\hline
\end{tabular}

With regard to scenarios 7 and 8 the effect of a change in Delivery Transport Time (DTT) is more straightforward since it only affects the Delivery to Customer Rate $(D R C)$ and consequently the Revenues from Sales $(R S)$ since customers pay for their ordered goods upon their receipt. A reduction in DTT leads to an increase in revenues and therefore Cash Balance, while an increase has the opposite effect (figure 3). A realistic extension of the model would be to assume delivery sensitive customers and link customer delivery time to Actual Demand. In this case the later variable will be considered to be endogenous and a function of delivery time, assuming that customer satisfaction and ultimately demand depends of Delivery Transport Time (DTT) 


\section{Conclusion}

Estimating the effect of FTTC can by no means considered a straightforward process. The simulation results demonstrated that the effect of FTTC on manufacturers depends strongly on the decision rules they apply and the time horizon of their reaction. Different parameters and values are expected to alter the results and lead to different FTTC values. According to the theory on the microeconomics effects of FTTC, the reactions of manufacturers to FTTC are numerous and may include reorganization of the ordering, inventory and production policy. In the paper we examined the effect that changes in the ordering policy of the manufacturer and their time profile can have on its economic performance. The result was rather intriguing showing that the company will have best results not in the case of a freight transport time saving but in the case of an increase in transportation time of goods from the supplier provided that the decision rules applied prior to the change continue to apply (scenario 4). Although other proposed by the literature strategies such as altering the desired inventory level of materials and finished goods were not explored in this research, their viability could be tested through the use of simulation modeling.

A second conclusion deriving from the above is that current methods used to elicit the value of FTTC may not safely measure this effect due to several reasons that have been discussed earlier and one more: it is impossible for managers to gather and process all the information needed to make best decisions especially in the long run. Plus, there are methodological difficulties in modeling business processes, since it is difficult to apply pure formal modeling, empirical observation and experimentation in firms. Simulation models provide the possibility to include estimations of difficult to measure factors allowing the inclusion of all important parameters based on real world data or on estimates from actors within firms (Grobler and Schieritz, 2005).

The use of Systems Dynamics for the estimation of the effect of FTTC on manufacturers revealed several advantages compared to the traditional RP and SP technics. First of all, time profiles for all variables are returned, from the initial time until the end of the time horizon allowing for comparisons between them with and without the exogenous stimuli (change in transportation time). Also, the gradual introduction of freight transport time changes is allowed along with alterations in decision rules and operating conditions of the firm resulting from them. Moreover, simulation allows the tracing of all variables' values and causes behind the results on a step by step basis.

Further research would include the relaxation of several assumptions regarding the transportation, inventory and production capacity as well as the examination of more business strategies in order for the model to be more realistic. 


\section{References}

Baumol, W. J. and Vinod, H. D. (1970), “An inventory theoretic model of freight transport demand", Management Science, 16(7), pp. 413-421.

Coyle, J.J., Novack, R.A., Gibson and B.J., Bardi E.J. (2010), "Transportation, A Supply Chain Perspective", 7th Edition, South-Weastern Cengage Learning, OH, USA.

Danielis R., Marcucci E. and Rotaris L. (2005), "Logistics Managers' Stated Preferences for Freight Service Attributes", Transportation Research Part E: Logistics and Transportation Review, Volume 41, Issue 3, pp: 201-215.

De Jong, G. D. (2000), "Value of Freight Transportation Time Savings", Hensher D.A. and Button K. J., Handbook of Transport Modelling, Emerald Group Publishing, pp. $553-$ 564.

Feo-Valero, M., García-Menéndez, L. and Garrido-Hidalgo, R. (2011), "Valuing freight transport time using transport demand modeling: A bibliographical review", Transport Reviews, Vol. 31, No. 5, 625-651.

Grobler, A. and Schieritz, N. (2005), "Of Stocks, Flows, Agents and Rules - Strategic Simulations" IN Kotzab, H., Westhaus M., Seuring, S. A., Muller, M., Reiner, G., (Editors) Supply Chain Research Methodologies in Supply Chain Management, Physica-Verlag, pp. 445-461.

Havlíček, K., Břečková, P. and Zampeta, V. (2013), "Quality Management as a Part of CRM”, European Research Studies Journal, Vol. XVI(4), 15-28.

Hensher, D.A. (2010), "Hypothetical Bias, Choice Experiments and Willingness to Pay" Transportation Research Part B, 44, pp.735-752.

Hensher, D.A., Rose J. and Greene W. H. (2005), "The Implications on Willingness to Pay of Respondents Ignoring Specific Attributes”, Transportation, 32, pp. 203-222.

Massiani, J. (2003), "Benefits of transportation time savings for freight transportation: Beyond the Costs", Paper presented at the European Regional Science Association Congress, available at: http://www-sre.wu-wien.ac.at/ersa/ersaconfs/ersa03/cdrom /abstracts/a388.html (accessed 1/2012).

Mohring, H. and Williamson, H.F. (1969), "Scale and Industrial Reorganization Economies of Transport Improvements", Journal of Transport Economics and Policy, 3 (3), pp. 251-272.

Morecroft J. (2007), "Strategic Modelling and Business Dynamics", A Feedback Systems Approach. John Wiley \& Sons, Chichester, UK.

Morikawa, T. (1994), "Correcting State Dependence and Serial Correlation in the RP/SP Combined Estimation Method", Transportation 21, pp.153-165.

Odgaard, T., Kelly, C. E. and Laird, J. J., (2005), "|Current Practice in Project Appraisal in Europe-Analysis of Country Reports", HEATCO Work Package No. 3 (Stuttgart: IER).

Ortúzar, J. de D. and Willumsen, L. G. (2001), "Modelling Transport", $4^{\text {th }}$ Edition, Wiley, UK.

Porter, M. E. (1990), "The Competitive Advantage of Nations", New York: The Free Press.

Porter, M., Delgado, M., Ketels, Ch. and Stern, S. (2008), "Moving to a New Global Competitiveness Index In World Economic Forum", The Global Competitiveness Report 2007-2008. Geneva: World Economic Forum. 
Porter, M., Ketels, Ch. and Delgado, M. (2007), "The Microeconomic Foundations of Prosperity: Findings from the Business Competitiveness Index In World Economic Forum", The Global Competitiveness Report 2007-2008. Geneva: World Economic Forum.

Ramfou, I. (2012), "Freight transportation as an inductive phenomenon of organisational performance", Phd Thesis, University of Piraeus.

Sambracos E. and Ramfou, I. (2013), "Freight Transport Time Savings and Organizational Performance: A Systemic Approach", International Journal of Economic Sciences and Applied Research (IJESAR), vol. 6(1), pp. 19-40.

Sterman J. (2000), "Business Dynamics, Systems Thinking and Modeling for a Complex World", Irwin McGraw-Hill, USA.

Tavasszy, L.A. (2008), "Measuring Value of Time in Freight Transport: A Systems Perspective", Ben-Akiva, M., Meersman, H. and Van de Voorde, E, Recent Developments in Transport Modelling, Lessons for the Freight Sector, Emerald Group Publishing.

Tavasszy, L.A. and Bruzelius, N. (2005), "The Value of Freight Transport Time: A Logistics Perspective - State of the Art and Research Challenges", Round Table 127: Time and Transport, OECD/ECMT, Paris.

Thalassinos, I.E. and Zampeta, V. (2012) "How Corporate Governance and Globalization Affect the Administrative Structure of the Shipping Industry", Journal of Global Business and Technology, Vol. 8(1), 48-52.

US Department of Transport (US DOT) Federal Highway Administration (FHWA) (2001), "Freight Benefit/Cost Study White Paper Benefit-Cost Analysis of Highway Improvements in Relation to Freight Transportation: Microeconomic Framework (Final Report)" Presented by the AECOM Team: ICF Consulting, HLB Decision Economics, Louis Berger Group, USA.

US Department of Transport (US DOT) Federal Highway Administration (FHWA) (2004), "Freight Transportation Improvements and the Economy", Washington, DC, USA.

Winston, C. (1983), "The demand for freight transportation: models and applications, Transportation", Research Part A, 17(6), pp. 419-427.

World Economic Forum (2011), “The Global Competitiveness Report 2011-2012”, Geneva: World Economic Forum.

Zamparini, L., and Reggiani A. (2007), "Freight Transport and the Value of Transportation Time Savings: A Meta-analysis of Empirical Studies", Transport Reviews, 27: 5, pp. $621-636$. 